\title{
Characterization of influenza virus sialic acid receptors in minor poultry species
}

\author{
Brian Kimble1, Gloria Ramirez Nieto ${ }^{1,2}$, Daniel R Perez ${ }^{1 *}$
}

\begin{abstract}
It is commonly accepted that avian influenza viruses (AIVs) bind to terminal $\alpha 2,3$ sialic acid (SA) residues whereas human influenza viruses bind to $\alpha 2,6$ SA residues. By a series of amino acid changes on the HA surface protein, AIVs can switch receptor specificity and recognize $\alpha 2,6$ SA positive cells, including human respiratory epithelial cells. Animal species, like pigs and Japanese quail, that contain both $\alpha 2,3$ and $\alpha 2,6$ SA become ideal environments for receptor switching. Here, we describe the SA patterns and distributions in 6 common minor domestic poultry species: Peking duck, Toulouse geese, Chinese ring-neck pheasant, white midget turkey, bobwhite quail, and pearl guinea fowl. Lectins specific to $\alpha 2,3$ and $\alpha 2,6$ SA (Maakia amurensis agglutinin and Sambuca nigra agglutinin, respectively) were used to detect SA by an alkaline phosphotase-based method and a fluorescent-based method. Differences in SA moieties and their ability to bind influenza viruses were visualized by fluorescent labeling of 4 different H3N2 influenza viruses known to be specific for one receptor or the other. The geese and ducks showed $\alpha 2,3$ SA throughout the respiratory tract and marginal $\alpha 2,6 \mathrm{SA}$ only in the colon. The four other avian species showed both $\alpha 2,3$ and $\alpha 2,6 \mathrm{SA}$ in the respiratory tract and the intestines. Furthermore, the turkey respiratory tract showed a positive correlation between age and $\alpha 2,6$ SA levels. The fact that these birds have both avian and human flu receptors, combined with their common presence in backyard farms and live bird markets worldwide, mark them as potential mixing bowl species and necessitates improved surveillance and additional research about the role of these birds in influenza host switching.
\end{abstract}

\section{Introduction}

Waterfowl act as the natural reservoir of influenza A viruses. Virus isolates from these birds show high binding preference towards glycans that terminate in sialic acids linked to galactose in an $\alpha 2,3$ conformation ( $\alpha 2,3$ $\mathrm{SA})$, the same receptor that dominates the duck intestinal and respiratory tracts $[1,2]$. These isolates typically show low infectivity in humans due in part to the prevalence in the respiratory tract of glycans terminating in sialic acid $(\alpha 2,6)$ galactose $(\alpha 2,6 \mathrm{SA})[3,4]$. However, stable, species specific, viral lineages have jumped from the natural reservoir to wild non-aquatic birds, domestic poultry, and many mammalian species, most notably swine and humans.

In order for an avian virus to infect a human, several changes must occur in the virus, most notably in the

\footnotetext{
* Correspondence: Dperez1@umd.edu

${ }^{1}$ Department of Veterinary Medicine, University of Maryland College Park, and Virginia-Maryland Regional College of Veterinary Medicine, 8075

Greenmead Drive, College Park, MD 20742, USA

Full list of author information is available at the end of the article
}

HA protein. This can happen in one of two ways: the build up of specific mutations (genetic/antigenic drift) or the recombination with a second virus with a suitable HA gene (genetic/antigenic shift). Both of these processes are facilitated by infection in a 'mixing bowl' species, a host that can accommodate both types of receptors. For example, swine express both sialic acid moieties and allowed it to play a critical role in the current $\mathrm{H} 1 \mathrm{~N} 1$ pandemic $[2,5]$.

The emergence of highly pathogenic avian influenza (HPAI) in people who have direct contact with poultry underscore the role poultry play in the transmission of influenza into humans, yet very little is known about the distribution of sialic acid receptors in most poultry species [6,7]. Thus, little is known of the potential of poultry species to act as mixing bowls. Previous studies have shown that mallard and Peking ducks display predominately $\alpha 2,3 \mathrm{SA}$ in both the intestinal tract and the respiratory tract [8-10]. White leghorn chicken and, particularly, Japanese quail show more $\alpha 2,6 \mathrm{SA}$ expression in the respiratory tract $[9,11]$.

\section{Biomed Central}


Typically, plant lectins that specifically bind to terminal SA are used to identify the distribution of SAs in tissues via lectin histochemistry. M. amurensis agglutinin (MAA) binds most predominantly to any glycan terminating in $\alpha 2,3$ SA while $S$. nigra agglutinin binds to terminal $\alpha 2,6$ SA $[12,13]$. Here we use two methods of lectin staining to describe the distribution of $\alpha 2,3 \mathrm{SA}$ and $\alpha 2,6 \mathrm{SA}$ in six poultry species: Peking duck, Toulouse goose, Chinese ring-neck pheasants, white midget turkey, bobwhite quail, and pearl guinea fowl. The first method is based on digoxigenin-linked lectins and HRP (horseradish peroxidase)-linked anti-digoxigenin antibodies that interact with a substrate to precipitate a marker visible by light microscopy. The second is based on fluorescently-labeled lectins that are visible under a fluorescent microscope.

These methods, however, do not directly measure a tissues capacity to bind influenza virus as there are many other variables that determine binding ability. Specific amino acid sequence and glycosylation in and near the receptor binding site of HA can shift binding specificity from $\alpha 2,3 \mathrm{SA}$ to $\alpha 2,6 \mathrm{SA}$ and vice versa. Additionally, these changes can shrink or expand the pool of specific glycans terminating in $\alpha 2,3$ SA or $\alpha 2,6$ SA that HA can bind $[14,15]$. Various modifications to the receptors can also change binding specificity $[16,17]$. To assuage these issues, we also used a virus-binding histochemistry technique to directly measure the virus binding patterns as they correlated to the SA distribution.

\section{Animal tissues}

One day-old Peking ducks, Toulouse geese, Chinese ringneck pheasants, white midget turkeys, bob white quail, and pearl guinea fowl were received from McMurray Hatchery (Webster City, IA). Animals were maintained in ABSL2 conditions in the Department of Veterinary Medicine for 4 weeks. In the case of ducks and geese, one animal was sacrificed for tissue collection at the age of 1, 2 and 4 weeks of age. For all other birds 2 animals were sacrificed for tissue collection at 1,2 , and 4 weeks of age. Japanese quail were hatched at the Department of Veterinary Medicine and maintained in ABSL2 conditions for 4 weeks. Two animals were sacrificed for tissue collection. The Institutional Animal Care and Use Committee of the University of Maryland, College Park, approved all animal studies. Animal studies adhere strictly to the US Animal Welfare Act (AWA) laws and regulations.

\section{Viruses}

A/duck/Hong Kong/375/1975 (H3N2) and A/turkey/ Ohio/313053/2004 (H3N2) were kindly provided by Robert Webster, St Judes Children's Research Hospital,
Memphis, TN and Yehia Saif, Ohio State University, Wooster, $\mathrm{OH}$, respectively. These viruses were grown in 10 day old embrionated chicken eggs and stocks prepared and maintained at $-70^{\circ} \mathrm{C}$ until use. A/Memphis/ 31/1998 (H3N2) was propogated in MDCK cells, stocks prepared and maintained at $-70^{\circ} \mathrm{C}$ until use.

\section{Tissue preparation and sectioning}

Trachea, lung, middle, and lower intestine were collected from each animal and rinsed in PBS for $5 \mathrm{~min}$ utes. Appropriate sized samples were wrapped in aluminum foil and frozen on dry ice. Samples were embedded in OCT and cut into $5 \mu \mathrm{m}$ thick sections by Histoserv (Germantown, MD).

\section{Digoxigenin sialic acid (SA) detection method}

Slides containing sections of tissue were rinsed for $1 \mathrm{~h}$ at room temperature in tap water before being fixed for 15 minutes in cold acetone followed by a 15 minute incubation in $2 \% \mathrm{H}_{2} \mathrm{O}_{2}$ in methanol. Slides were rinsed 3 times for 5 minutes in tris-buffered saline (TBS) buffer and blocked over night at $4{ }^{\circ} \mathrm{C}$ in $1 \%$ BSA (Sigma, Lenexa, KS) in TBS. Tissue was stained using DIG glycan differentiation kit (Roche, Mannheim, Germany). Briefly, slides were incubated for 1 hour at room temperature in digoxigenin (DIG)-labeled $M$. amurensis agglutinin (MAA, specific for $\alpha 2,3 \mathrm{SA}$ ) or DIG-labled S. nigra agglutinin (SNA, specific for $\alpha 2,6 \mathrm{SA}$ ) in TBS. Following 3 rinses in TBS, slides were then incubated for 1 hour in peroxidase labeled anti-DIG fragments at room temperature. Three more washes in TBS were followed by 10 minute incubation in aminoethylcarbazole (AEC) (DAKO, Glostrup, Denmark) and counterstained in hematoxylin for 30 minutes. Cover slips were mounted using aqueous mounting media and tissues were observed under $400 \times$ magnification.

\section{Fluorescent sialic acid detection method}

Slides were fixed and blocked similarly as described for the DIG-based method. Tissues were stained by incubating in FITC-labeled SNA (EY Laboratories, San Mateo, CA) and TRITC-labeled MAA or FITC-labeled MAA and TRITC-labeled SNA for 1 hour at room temperature. Following 3 rinses in TBS, slides were stained for 5 minutes in DAPI (4',6-Diamidino-2-phenylindole, dihydrocholride from Thermo Scientific Rockford, IL). Cover slips were mounted over the tissue using fluorescent mounting media (KPL, Gaithersburg, MD) and imaged at $400 \times$ or $630 \times$ magnification.

\section{Virus binding assay}

Allantoic fluid or tissue culture supernatant was harvested and concentrated using the Centricon Plus-70 system from Millipore (Billerica, MA). Tissue was fixed 
and blocked as described in Digoxigenin sialic acid detection section. Approximately $600 \mathrm{HAU}$ of virus was mixed 1:1 with $1 \%$ BSA in PBS and incubated on the tissue at $37^{\circ} \mathrm{C}$ for 2 hours. The virus was fixed after rinsing with $50 / 50$ acetone/methanol for $15 \mathrm{~min}$. at $-20^{\circ} \mathrm{C}$. The tissue was then incubated for 1 hour at room temperature with a monoclonal antibody specific to NP. Following three washes in phosphate buffered solution (PBS), the tissue was incubated in FITC-labeled antimouse antibody for one hour at room temperature in the dark. The tissue was then stained with DAPI and visualized with a fluorescent microscope at 400x.

\section{Results and Discussion}

Waterfowl and land land based poultry species differ in sialic acid distribution in various tissues

Lectin-based staining assays were used to determine the variations in sialic acid form and tissue distribution in various poultry species. Trachea, lung, and large intestine from 6 minor poultry species were used to determine the distribution of SA receptors. Ducks were included as a control as it has previously been reported that they show predominantly $\alpha 2,3 \mathrm{SA}$ in the trachea with increasing $\alpha 2,6$ on epithelial lining farther along the respiratory tract and only minimal $\alpha 2,6$ in the large intestine [10]. All other species were chosen for their presence in live poultry markets across the world.

The results indicate that there is a distinct difference between waterfowl (duck and goose) and land-based poultry (pheasant, turkey, bobwhite quail, and guinea fowl)

Table 1 Relative expression of sialic acid in avian tissues.

\begin{tabular}{|c|c|c|c|c|c|c|c|}
\hline \multirow[t]{2}{*}{ Species } & \multirow[t]{2}{*}{ Age (Week) } & \multicolumn{2}{|c|}{ Trachea } & \multicolumn{2}{|c|}{ Lung } & \multicolumn{2}{|c|}{ Large intestine } \\
\hline & & 2,3 & 2,6 & 2,3 & 2,6 & 2,3 & 2,6 \\
\hline \multirow[t]{3}{*}{ Duck } & 1 & + & - & + & + & + & - \\
\hline & 2 & + & - & ++ & + & ++ & + \\
\hline & 4 & + & - & ++ & + & ++ & + \\
\hline \multirow[t]{3}{*}{ Goose } & 1 & + & - & + & + & + & - \\
\hline & 2 & + & - & + & + & ++ & + \\
\hline & 4 & + & - & + & - & + & + \\
\hline \multirow[t]{3}{*}{ Pheasant } & 1 & ++ & + & + & + & + & + \\
\hline & 2 & ++ & + & + & + & + & + \\
\hline & 4 & ++ & + & + & + & + & + \\
\hline \multirow[t]{3}{*}{ Turkey } & 1 & ++ & + & + & + & + & - \\
\hline & 2 & ++ & + & + & + & + & - \\
\hline & 4 & ++ & ++ & ++ & ++ & + & - \\
\hline \multirow[t]{3}{*}{ Guinea fowl } & 1 & + & + & + & + & + & - \\
\hline & 2 & + & + & + & + & + & - \\
\hline & 4 & + & + & + & + & + & - \\
\hline \multirow[t]{3}{*}{ Quail } & 1 & + & + & + & + & + & - \\
\hline & 2 & + & + & + & + & + & - \\
\hline & 4 & + & + & + & + & + & - \\
\hline
\end{tabular}

- no expression, + minimal expression, ++ moderate-high expression.
(Table 1) in terms of presence and distribution of SA receptors, particularly $\alpha 2,6$. There were also age-based differences observed, particularly in turkeys (Table 1).

In the trachea, the ducks showed moderate to high levels of $\alpha 2,3$ SA (Table 1 and Figure 1A, B, C), consistent with previous reports $[10,18]$. There was no expression of $\alpha 2,6 \mathrm{SA}$, consistent with one report [10], but not the other [18]. The geese trachea also showed an abundance of $\alpha 2,3$ SA and absence of $\alpha 2,6$ SA at any age (Table 1 and Figure 1D, E, F). On the contrary, the four land-based species showed both forms of sialic acid at all ages tested with positive staining of mucin-producing cells lining the lumen of the trachea (Table 1 and Figure $1 G-R)$. Farther down the respiratory tract, the lungs (Figure 2) tested positive for both SA forms in all birds of all ages with the only exception being in the goose. Staining was present on cells lining the lumen of the lungs. Strong positive staining for both types of SA receptors was observed in the lungs of turkeys (Figure 2J, K), consistent with the observation of influenza outbreaks in turkeys caused by swine influenza viruses with human-like receptor specificity. The lungs of guinea fowl showed also significant staining for both SA receptors, which is consistent with the circulation in these birds of H9N2 viruses with human-like receptor specificity. At 4 weeks of age, no $\alpha 2,6$ SA was detected in the goose's lung (Figure 2E, F). However, both $\alpha 2,3$ $\mathrm{SA}$ and $\alpha 2,6 \mathrm{SA}$ were seen in the lung samples from geese at weeks 1 and 2 (not shown).

Testing of the large intestine once again showed a divide between the species. All six species tested positive for $\alpha 2,3 \mathrm{SA}$ in the large intestine in cells facing the lumen (Figure 3). However, duck, goose, and pheasant large intestine also showed minimal positive results for $\alpha 2,6 \mathrm{SA}$ (Figure 3B, E and 3H) while turkey, guinea fowl and quail tested negative (Figure $3 \mathrm{~K}, \mathrm{~N}$ and $3 \mathrm{Q}$; please note that significant $\alpha 2,6 \mathrm{SA}$ staining was observed on the basolateral side - opposite to the intestinal lumen of epithelial cells in guinea fowl.)

The birds can be divided into three groups based on the distribution of sialic acids in the tissues examined. The waterfowl, the natural host of avian influenza viruses, show predominantly $\alpha 2,3 \mathrm{SA}$ in their tissues. $\alpha 2,6 \mathrm{SA}$ is only seen in the lower respiratory tract and minimally in the large intestine. The land-based birds also express $\alpha 2,3 \mathrm{SA}$ in all the tissues tested, however, they also express significant levels of $\alpha 2,6 \mathrm{SA}$ in the upper respiratory tract. This could help explain why these birds are susceptible to AIVs resulting in the emergence of strains with altered receptor specificity, including with human-like receptor binding [19]. This also underscores the potential role of these birds in influenza virus reassortment. Finally, the pheasants 


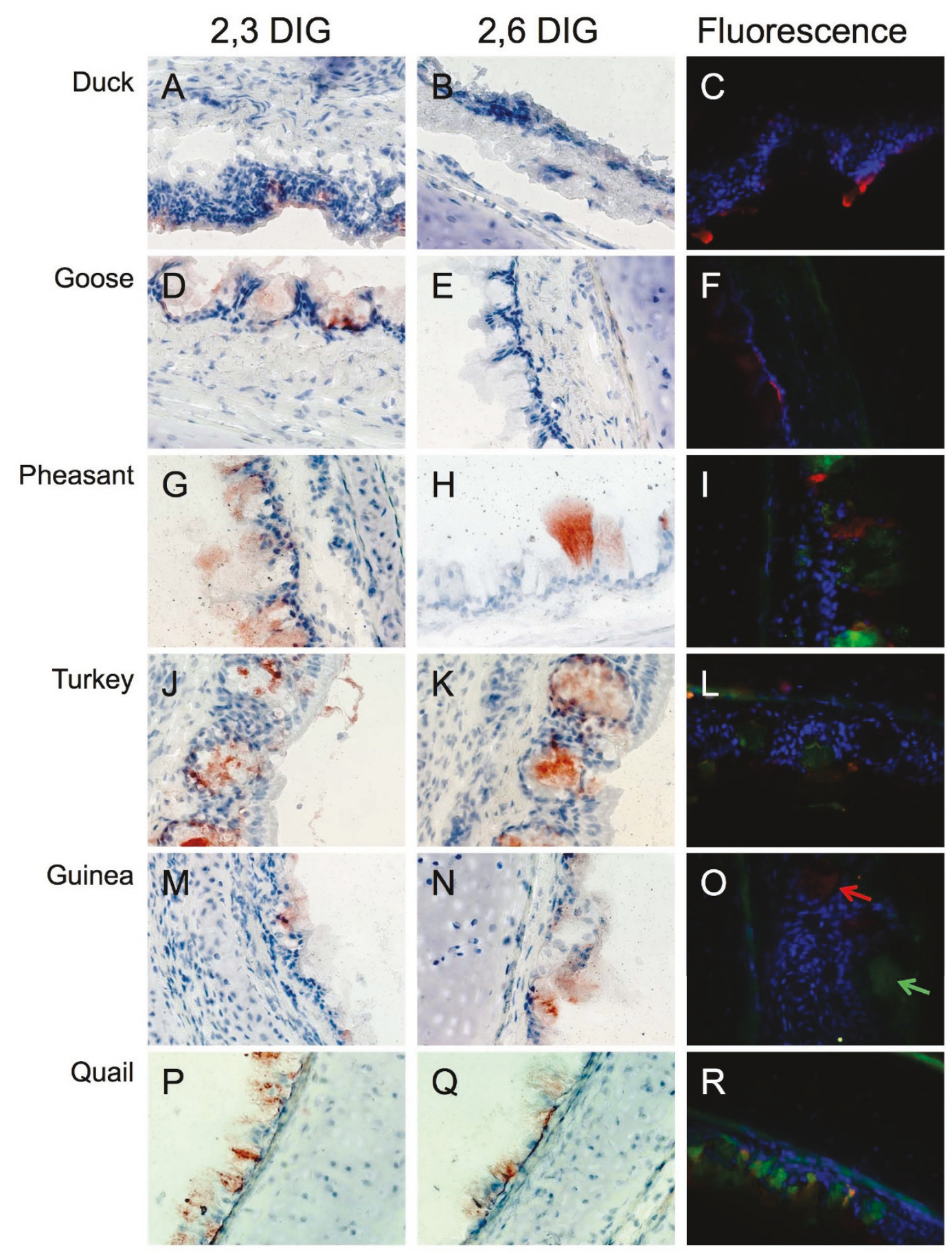

Figure 1 Sialic acid distribution in avian trachea. Representative sections of trachea from 4 week old duck $(A, B, C)$, goose $(D, E, F)$, pheasant $(G, H, I)$, turkey $(J, K, L)$, quail $(M, N, O)$, and guinea fowl $(P, Q, R)$ stained with either DIG labeled MAA ( $\alpha 2,3$ specific, first column), DIG labeled SNA ( $\alpha 2,6$ specific, second column) or FITC SNA (green $\alpha 2,6$ ) and TRITC MAA (red $\alpha 2,3$ ). Duck and goose trachea show only $\alpha 2,3$ SA while all other birds display both $\alpha 2,3$ and $\alpha 2,6$ SA. 


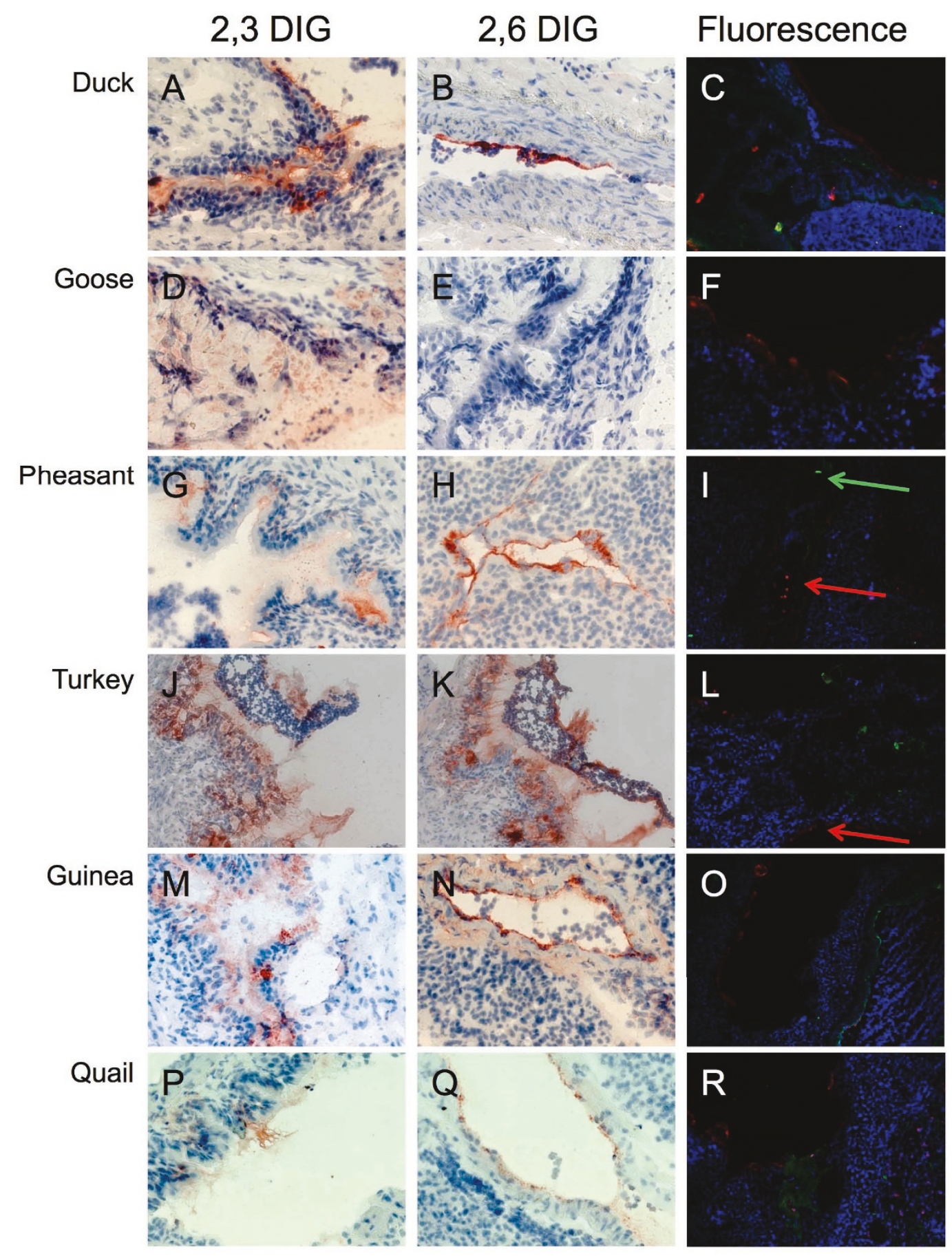

Figure 2 Sialic acid distribution in avian lung. Representative sections of lung from 4 week old duck $(A, B, C)$, goose $(D, E, F)$, pheasant $(G, H, I)$, turkey $(J, K, L)$, quail $(M, N, O)$, and guinea fowl $(P, Q, R)$ stained with either DIG labeled MAA ( $\alpha 2,3$ specific, first column), DIG labeled SNA ( $\alpha 2,6$ specific, second column) or FITC SNA (green $\alpha 2,6$ ) and TRITC MAA (red $\alpha 2,3)$. Goose lung shows only $\alpha 2,3$ SA while all other birds display both $\alpha 2,3$ and $\alpha 2,6$ SA. 


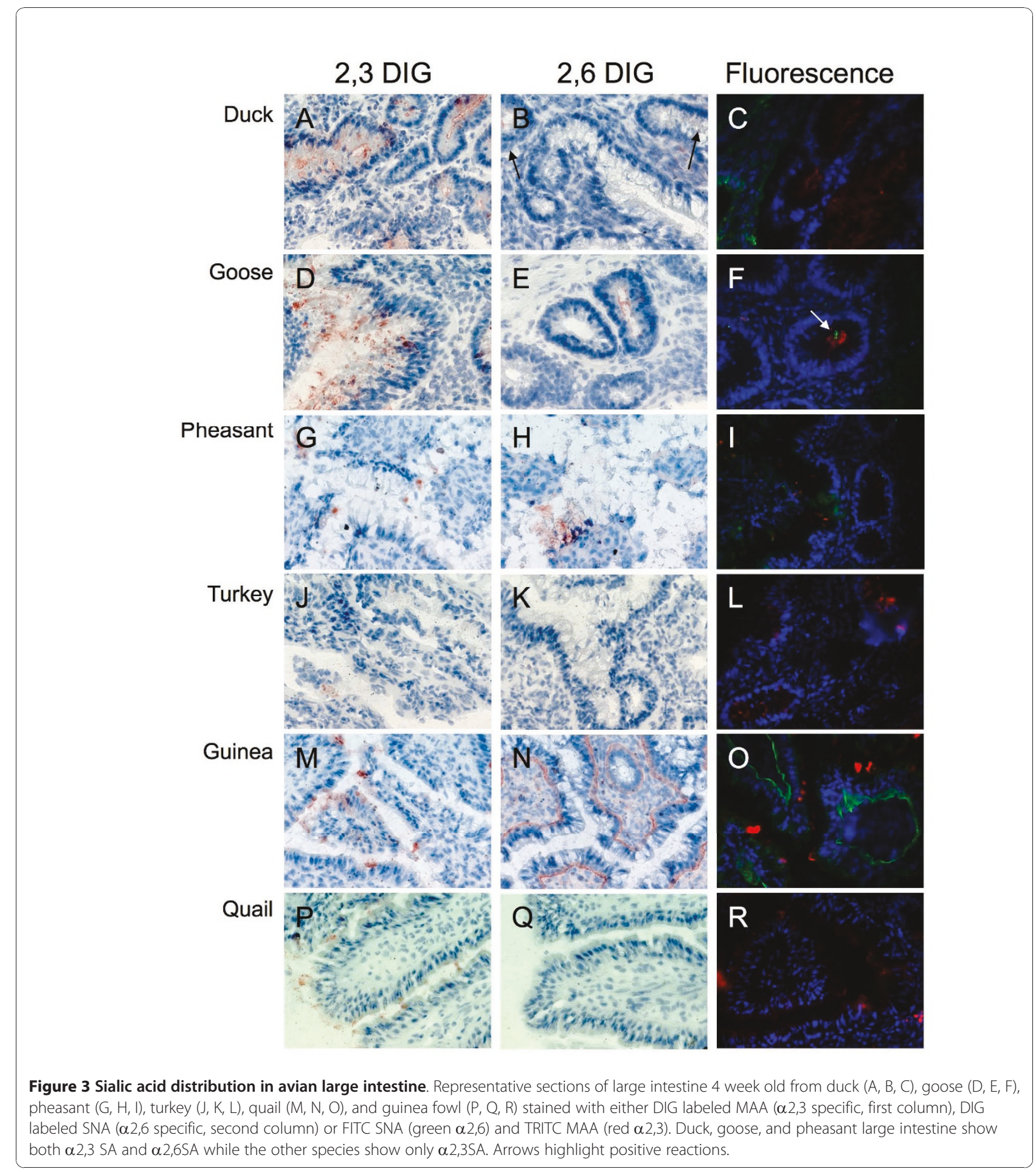

showed $\alpha 2,6 \mathrm{SA}$ in the trachea similar to the other land birds, but also showed $\alpha 2,6 \mathrm{SA}$ in the large intestine like the aquatic birds. This could make the pheasant more likely than other species to facilitate viral reassortment or to act as a "mixing bowl" species.
Age dependent variations in $\alpha 2,6 \mathrm{SA}$ expression

While performing the experiments described above a trend was noticed in three species. The ducks and geese showed an increasing expression of $\alpha 2,6 \mathrm{SA}$ in the large intestine as they aged. Similarly, an increase in $\alpha 2,6 \mathrm{SA}$ 


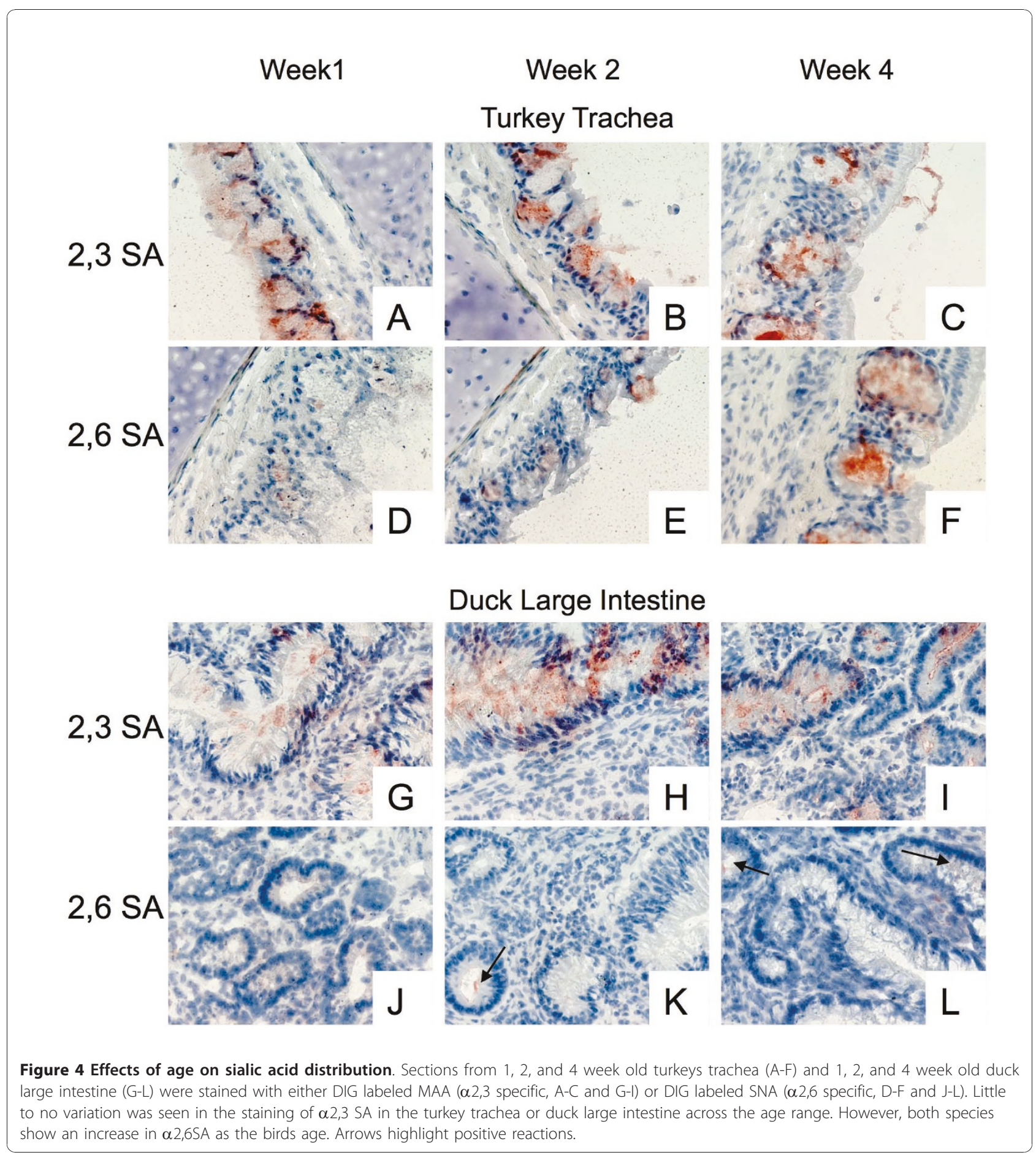

detection was seen in the trachea of turkeys as they aged. The age dependence in turkeys was later reported by Pillai and Lee [18], however, they did not see any increase in $\alpha 2,6$ in Pekin ducks. There was no detection of $\alpha 2,6 \mathrm{SA}$ in the large intestine of ducks and geese at week 1 (Figure 4J for duck, not shown for geese). However, by week 2 there was a very low level positive reaction and at week 4 this reaction was slightly increased (Figure $4 \mathrm{~K}$ and $4 \mathrm{~L}$ arrows). Expression levels of $\alpha 2,3 \mathrm{SA}$ remained relatively constant (Figure 4G-I) at all three time points.

In the turkey trachea this change in expression was even more pronounced. At week 1 (Figure 4D) only minimal $\alpha 2,6$ SA was detected. A week later (Figure 4E) 
there was a moderate positive response. By week 4 (Figure 4F) there was high level of expression. Again, there was no change in expression $\alpha 2,3 \mathrm{SA}$ at all time points (Figure 4A-C). No major age-related changes were observed in the other avian species tested for either 2,3 or 2,6 SA expression. This changing receptor pattern could have effects for live attenuated vaccines against viruses with a $\alpha 2,6$ binding preference in young turkeys and in ovo inoculations.

\section{Lectin binding patterns are not indicative of virus binding patterns}

Glycan micro arrays have shown that not all $\alpha 2,3 \mathrm{SA}$ or $\alpha 2,6 \mathrm{SA}$ bind to influenza HA proteins equally well [15]. One glycan terminating in $\alpha 2,3$ SA might not bind HA while another may bind exceedingly well [15]. Unfortunately, both will show a positive reaction to the lectin-binding assays. Thus, determining the influenza virus-binding profile in tissues of different animal species is a condition sine qua non to better understand the role of these receptors.

Three H3N2 influenza viruses were selected to determine the correlation between lectin binding and virus binding using 3 prototypic $\mathrm{H} 3 \mathrm{~N} 2$ viruses to ensure differences were due to receptor specificity and not differences between subtypes. To determine the binding affinity of each virus, hemaglutinin agglutination assays were performed for each virus. According to previous reports, horse red blood cells (RBCs) express solely $\alpha 2,3$ SA on their surface while pig RBCs express predominantly $\alpha 2,6 \mathrm{SA}[20]$. By comparing HA titers determined with each blood type, a binding preference can be ascertained. A/Dk/HK/7/75 (A/Dk) is a typical AIV duck isolate that bound horse $\mathrm{RBCs}$ twice as readily as pig $\mathrm{RBCs}$, indicating a strong $\alpha 2,3 \mathrm{SA}$ preference (Table 2). $\mathrm{A} / \mathrm{Tk} / \mathrm{OH} / 313053 / 04$ (A/Tk) was isolated from a turkey and bound pig RBCs slightly higher than horse RBCs, indicating a slight preference for $\alpha 2,6 \mathrm{SA}$ (Table 2). $\mathrm{A} / \mathrm{Memphis} / 31 / 98(\mathrm{~A} / \mathrm{Mem})$ is a human origin virus that shows no $\alpha 2,3 \mathrm{SA}$ binding[21]. Accordingly, A/Mem only showed HA titer with the pig RBCs (Table 2). Using these three viruses we were able to determine the accuracy and resolution of the lectin binding results.

The trachea of the duck and geese showed no $\alpha 2,6$ SA. The virus-binding assay showed no binding to the

Table 2 Hemaglutinin binding affinity of H3N2 viruses.

\begin{tabular}{ccccc}
\hline & \multicolumn{2}{c}{ Horse Red Blood Cells } & \multicolumn{2}{c}{ Pig Red Blood Cells } \\
\cline { 2 - 5 } & HA titer* & StDv & HA titer* & StDv \\
\cline { 2 - 5 } A/DK & 64 & 0 & 32 & 0 \\
A/TK & 3 & \pm 1.15 & 7 & \pm 2 \\
A/Memphis & 0 & 0 & 20 & \pm 8 \\
\hline
\end{tabular}

*Average of 4 assays

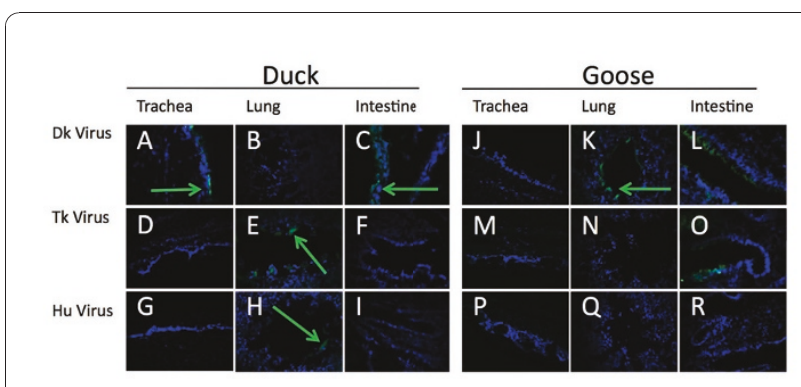

Figure 5 Viruses binding to tissues correlates to sialic acid distribution in domestic ducks and geese. Sections from 4 week old Peking duck (A-I) and Toulouse goose(J-R) tissues were exposed to A/DK/HK/7/75 (A-C, J-L), A/TK/OH/313053/04 (D-F, M-O), or A/ Memphis/31/98 (G-I, P-R). Virus presence (green) was detected by $\alpha$ NP monoclonal antibodies and FITC linked $\alpha$-mouse antibodies. Cells nuclei were stained with DAPI (blue).

$\mathrm{A} / \mathrm{Mem}$ or the $\mathrm{A} / \mathrm{Tk}$ viruses (Figure $5 \mathrm{~A}, \mathrm{D}, \mathrm{J}$ and $5 \mathrm{M}$ ). Additionally, there was minimal binding of $\mathrm{A} / \mathrm{Dk}$ to the duck trachea (Figure 5G) and no virus binding of the A/ $\mathrm{Dk}$ to the goose trachea despite ample expression of $\alpha 2$,3SA (Figure $5 \mathrm{P}$ ). This is not unexpected as the typical route of infection in waterfowl is through the cloacae. In contrast, pheasant and turkey trachea exhibited the ability to bind all three viruses (Figure 6A, D, G, J, $\mathrm{M}$ and $6 \mathrm{P}$ ). Based on fluorescent intensity and distribution of the fluorescent signal, in the pheasant the A/Dk virus showed the lowest levels of binding while the turkey showed equal binding between the three viruses. The quail trachea showed low binding with A/Dk and $\mathrm{A} / \mathrm{Tk}$, and no binding of the human $\mathrm{A} / \mathrm{Mem}$ virus (Figure 7J, M, and 7P). The guinea fowl, on the other hand showed low levels of binding with $\mathrm{A} / \mathrm{Mem}$ but no binding with A/Dk or A/Tk (Figure 7A, D and 7G).

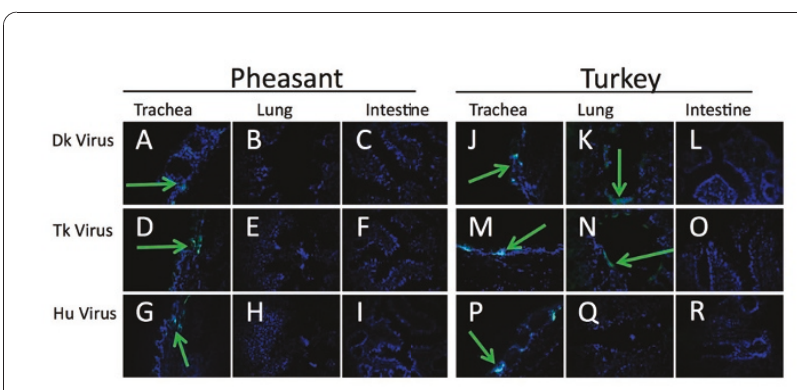

Figure 6 Viruses binding to tissues correlates to sialic acid distribution in domestic turkeys and pheasant. Sections from 4 week old white midget turkey $(A-l)$ and Chinese ringneck pheasants (J-R) tissues were exposed to A/DK/HK/7/75 (A-C, J-L), A/TK/OH/ 313053/04 (D-F, M-O), or A/Memphis/31/98 (G-I, P-R). Virus presence (green) was detected by $\alpha$ NP monoclonal antibodies and FITC linked $\alpha$-mouse antibodies. Cells nuclei were stained with DAPI (blue). 


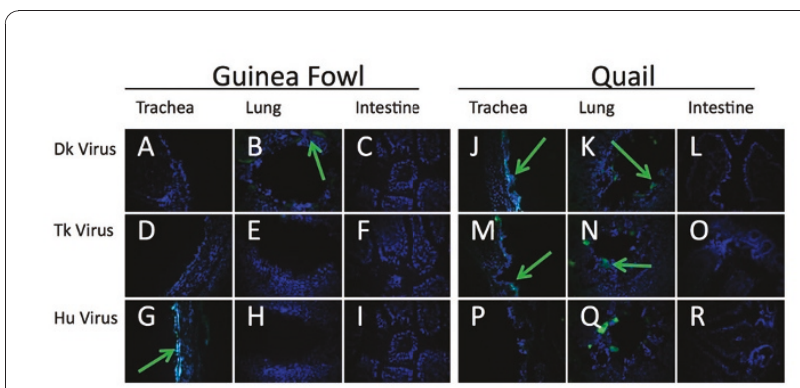

Figure 7 Viruses binding to tissues correlates to sialic acid distribution in domestic quail and guinea fowl. Sections from 4 week old bobwhite quail (A-I) and pearl guinea fowl (J-R) tissues were exposed to A/DK/HK/7/75 (A-C, J-L), A/TK/OH/313053/04 (D-F $\mathrm{M}-\mathrm{O}$ ), or A/Memphis/31/98 (G-I, P-R). Virus presence (green) was detected by $\alpha$ NP monoclonal antibodies and FITC linked $\alpha$-mouse antibodies. Cells nuclei were stained with DAPI (blue).

To visualize the virus binding in the lungs, we imaged transversal sections of the parabronchi to minimize variations from section to section and from species to species. Whenever virus was seen in these sections, it was seen binding to the smooth atrial muscles lining the parabronchi regardless of bird species or virus. The lungs of ducks showed moderate binding of $\mathrm{A} / \mathrm{Tk}$ and $\mathrm{A} / \mathrm{Mem}$ but no binding to A/Dk (Figure 5B, E and $5 \mathrm{H}$ ). The goose lung however showed binding with $\mathrm{A} / \mathrm{Dk}$ (Figure 5K) but no binding with the other two viruses (Figure $5 \mathrm{~N}$ and $5 \mathrm{Q}$ ). Pheasants showed no binding of any virus in the parabronchi (Figure $6 \mathrm{~B}, \mathrm{E}$ and $6 \mathrm{H}$ ). Turkey showed low to moderate binding of $\mathrm{A} / \mathrm{Dk}$ and $\mathrm{A} /$ Tk but no binding of A/Mem (Figure $6 \mathrm{~K}, \mathrm{~N}$ and $6 \mathrm{Q}$ ) while the guinea fowl had A/Dk binding but neither of the other two viruses (Figure 7B, E and 7H). Finally the quail were the only species to show binding of all three viruses in the lungs (Figure $7 \mathrm{~K}, \mathrm{~N}$ and $7 \mathrm{Q}$ ).

Despite the fact that all birds expressed $\alpha 2,3 \mathrm{SA}$ in the intestines, only the ducks and the geese showed any ability to bind A/Dk in the intestines. The four land based poultry species showed no binding despite showing expression of $\alpha 2,3 \mathrm{SA}$. The duck, goose and pheasant intestines also showed minor $\alpha 2,6$ SA expression. However, only A/Tk was able to bind and only in the intestines of the geese (Figure 5L). These results highlight the complexities associated with understanding the host range of influenza viruses. Although many studies, including ours, have looked at the expression of SA receptors in tissues of several animal species, these receptors are not necessarily capable of binding influenza viruses (at least not under the conditions tested in this report). More studies are needed to better ascertain to which extent different animal species are likely hosts of influenza viruses and which minimal changes in receptor binding are needed to establish productive infections in these hosts.

\section{Acknowledgements}

We would like to thank Yonas Araya and Ivan Gomez Osorio for their assistance with animal studies. We are indebted to Andrea Ferrero and Theresa Wolter Marth for their excellent laboratory managerial skills. The opinions of this manuscript are those of the authors and do not necessarily represent the views of the granting agencies. This research was made possible through funding by the CDC-HHS grant (1U01CI000355), NIAID-NIH grant, (R01AI052155), CSREES-USDA grant (2005-05523), and NIAID-NIH contract (HHSN266200700010C). The funders had no role in study design, data collection and analysis, decision to publish, or preparation of the manuscript.

\section{Author details}

${ }^{1}$ Department of Veterinary Medicine, University of Maryland College Park, and Virginia-Maryland Regional College of Veterinary Medicine, 8075 Greenmead Drive, College Park, MD 20742, USA. ${ }^{2}$ Facultad de Medicina Veterinaria y Zootecnia, Universidad Nacional de Colombia, Carrera 30 No. 45-03, Edificio 561B, Bogota, Colombia.

\section{Authors' contributions}

BK carried out the animal care, tissue staining, virus binding assays and drafted the manuscript. GRN carried out the animal care and participated in the study design. DRP conceived of the study, and participated in its design and coordination. All authors read and approved the final manuscript.

\section{Competing interests}

The authors declare that they have no competing interests.

Received: 11 October 2010 Accepted: 9 December 2010 Published: 9 December 2010

\section{References}

1. Alexander DJ: A review of avian influenza in different bird species. Vet Microbiol 2000, 74:3-13.

2. Ito T, Couceiro JN, Kelm S, Baum LG, Krauss S, Castrucci MR, Donatelli I, Kida H, Paulson JC, Webster RG, Kawaoka Y: Molecular basis for the generation in pigs of influenza A viruses with pandemic potential. J Virol 1998, 72:7367-7373.

3. Couceiro JN, Paulson JC, Baum LG: Influenza virus strains selectively recognize sialyloligosaccharides on human respiratory epithelium; the role of the host cell in selection of hemagglutinin receptor specificity. Virus Res 1993, 29:155-165.

4. Beare AS, Webster RG: Replication of avian influenza viruses in humans. Arch Virol 1991, 119:37-42.

5. Scholtissek C, Hinshaw VS, Olsen CW: Influenza in Pigs and their role as the intermediate host. In Textbook of Influenza. Edited by: Nicholson KG, Webster RG, Hay AJ. Oxford: Blackwell Science Ltd; 1998:137-145.

6. Peiris $M$, Yuen KY, Leung CW, Chan KH, Ip PL, Lai RW, Orr WK, Shortridge KF: Human infection with influenza H9N2. Lancet 1999, 354:916-917.

7. Subbarao K, Klimov A, Katz J, Regnery H, Lim W, Hall H, Perdue M, Swayne D, Bender C, Huang J, et al: Characterization of an avian influenza A (H5N1) virus isolated from a child with a fatal respiratory illness. Science 1998, 279:393-396.

8. Gambaryan A, Webster R, Matrosovich M: Differences between influenza virus receptors on target cells of duck and chicken. Arch Virol 2002, 147:1197-1208.

9. Wan H, Perez DR: Quail carry sialic acid receptors compatible with binding of avian and human influenza viruses. Virology 2006, 346:278-286.

10. Kuchipudi SV, Nelli R, White GA, Bain M, Chang KC, Dunham S: Differences in influenza virus receptors in chickens and ducks: implications for interspecies transmission. J Mol Genet Med 2009, 3:9.

11. Perez DR, Lim W, Seiler JP, Yi G, Peiris M, Shortridge KF, Webster RG: Role of quail in the interspecies transmission of $\mathrm{H} 9$ influenza $A$ viruses: molecular changes on HA that correspond to adaptation from ducks to chickens. J Virol 2003, 77:3148-3156.

12. Baum LG, Paulson JC: Sialyloligosaccharides of the respiratory epithelium in the selection of human influeza virus receptor specificity. Acta Histochemistry Suppl 1990, 40:4.

13. Shinya K, Ebina M, Yamada S, Ono M, Kasai N, Kawaoka Y: Avian flu: influenza virus receptors in the human airway. Nature 2006, 440:435-436. 
14. Suzuki Y: Sialobiology of influenza: molecular mechanism of host range variation of influenza viruses. Biol Pharm Bull 2005, 28:399-408.

15. Stevens J, Blixt O, Chen LM, Donis RO, Paulson JC, Wilson IA: Recent avian H5N1 viruses exhibit increased propensity for acquiring human receptor specificity. J Mol Bio 2008, 381:13.

16. Wu W, Air GM: Binding of influenza viruses to sialic acids: reassortant viruses with $\mathrm{A} / \mathrm{NWS} / 33$ hemagglutinin bind to alpha2,8-linked sialic acid. Virology 2004, 325:11

17. Gambaryan A, Tuzikov A, Pazynina G, Bovin N, Balish A, Kilmov A: Evolution of the receptor binding phenotype of influenza $A(H 5)$ viruses. Virology 2006, 344:7.

18. Pallai SPaL, Chang W: Species and age related differences in the type and distribution of influenza virus receptors in different tissues of chickens, ducks and turkeys. Virology journal 2010, 7.

19. Wan H, Perez DR: Amino acid 226 in the hemagglutinin of H9N2 influenza viruses determines cell tropism and replication in human airway epithelial cells. J Virol 2007, 81:5181-5191.

20. Ito T, Suzuki Y, Mitnaul L, Vines A, Kida H, Kawaoka Y: Receptor specificity of influenza $A$ viruses correlates with the agglutination of erythrocytes from different animal species. Virology 1997, 227:493-499.

21. Kshama Kumari SG, Smith FDavid, Upma Gulati, Cummings DRichard, Air MGillian: Receptor binding specificity of recent human H3N2 influenza viruses. Virology Journal 2007, 4.

doi:10.1186/1743-422X-7-365

Cite this article as: Kimble et al: Characterization of influenza virus sialic acid receptors in minor poultry species. Virology Journal 2010 7:365.

\section{Submit your next manuscript to BioMed Central and take full advantage of:}

- Convenient online submission

- Thorough peer review

- No space constraints or color figure charges

- Immediate publication on acceptance

- Inclusion in PubMed, CAS, Scopus and Google Scholar

- Research which is freely available for redistribution

Submit your manuscript at www.biomedcentral.com/submit 